\title{
Simulation of Airflow and Wind Pressure Coefficient in a Naturally Ventilated Classroom Model Using Environmental Wind Tunnel and CFD Modelling
}

\section{Radha Goyal ${ }^{1 *}$ and Mukesh Khare ${ }^{2}$}

${ }^{1}$ Scientist Fellow, National Environmental Engineering Research Institute (NEERI), Delhi Zonal Laboratory, CSIR R\&D centre, Naraina Industrial Area, Delhi, India ${ }^{2}$ Professor, Department of Civil Engineering, Indian Institute of Technology, Delhi, Hauz Khas, New Delhi, India

\begin{abstract}
The article presents an experimental study, which has been carried out in an environmental wind tunnel to measure the mean pressures and pressure differences at inlet and outlet of various openings of a naturally ventilated classroom model of a school building located near an urban roadway in the city of Delhi. The wind pressure coefficients have been measured and analyzed for different wind incidence angles and for varying classroom opening configurations representing the change in behavior of building occupants in different seasons of the year. The article also presents the results of a CFD modeling carried out to estimate the wind velocity and turbulent intensity in and around the classroom model to understand the actual airflow pattern inside the classroom. The present study is an effort to understand the occurrence of ventilation in naturally ventilated buildings and finally to evaluate the indoor air quality in such buildings.
\end{abstract}

Keywords: Naturally Ventilated Buildings; Wind Pressure Coefficient; Environmental Wind Tunnel; Computational Fluid Dynamics; Indoor Air Quality

\section{Introduction}

Urban areas are increasingly becoming polluted with increase in the number of industries, vehicles along with factors like reduction in forested areas to make way for various activities. This makes indoor spaces in urban areas prone to pollutants from outside which is compounded by factors like defects and leakage in buildings as well as climatic conditions which may transfer the pollutants from outside to the interiors.

Natural ventilation in buildings can create a comfortable and healthy indoor environment. It replaces indoor polluted air with fresh outdoor air without using mechanical power and thus save the energy consumed by the heating, ventilating and air-conditioning systems in a building if it provides acceptable indoor air quality (IAQ) and thermal comfort levels [1]. In a naturally ventilated building, air is driven in and out due to pressure difference produced by wind or buoyancy forces. Though natural ventilation is conceptually simple, its detailed design as the ventilation performance can be a challenge as intake air is not usually controlled and it involves the influence of building's type, its surroundings and climate. It is even more difficult in cases of wind driven ventilation, where effects of turbulence dominate $[2,3]$. Wind causes variable surface pressures on building's exterior surface that depends on the wind direction and speed, air density, surface orientation, and surrounding conditions. It changes the intake and exhaust system flow rates, infiltration, exfiltration and interior pressures in the buildings and therefore becomes the predominant driving force for ventilation [4]. Therefore, investigation of wind pressure distributions on buildings and the influence of environmental factors on it is an important field of investigation to understand the working of natural ventilation. Some researchers have tried to determine pressure profiles on buildings for different incidences [5,6], neighbor buildings configurations [7] or local environment densities [8]. Others try to describe buildings or topography influence on wind flow $[9,10]$. Some have investigated particular configurations as street canyon [11]. However, a systematic approach is necessary to obtain effective comprehension of pressure distributions on buildings to evaluate the IAQ as well as of thermal comfort levels of the buildings.

The above studies have also shown that the onsite measurement of airflow characteristics and the interpretation of its role in ventilation effectiveness is a very difficult task in naturally ventilated structures. Therefore, various models and tools have been used by building designers, IAQ and comfort experts to estimate the airflow rate, the dispersion of contaminants and the ventilation efficiency. These models range from simple empirical algorithms to calculate the global airflow rate to sophisticated CFD techniques based on Reynolds averaged Navier-Stokes (RANS) method [12-14].

In present study, an effort has been made to calculate the wind pressure coefficients (Cp) at the interior and exterior of the openings in a naturally ventilated classroom. An environmental wind tunnel (EWT) study has been carried out for simulation of pressure distribution inside and outside the classroom of a naturally ventilated school building, pressure coefficient $(\mathrm{Cp})$ and airflow pattern with varying classroom conditions e.g. in fully and partially opened, and fully closed windows and doors. An alternative computational fluid dynamic (CFD) modeling has also been carried out to calculate the wind velocity and turbulent intensity and to observe the airflow distributions in and around the classroom model.

\section{Site Selection and Experimental Setup}

A low rise (three-story) naturally ventilated school building located near a busy road and a fly over in urban vicinity and surrounded by commercial and residential area has been selected for the study. The classrooms selected for wind tunnel study are with dimensions of $7.57 \mathrm{~m} \times 6.02 \mathrm{~m} \times 3.90 \mathrm{~m}$. Each classroom is having three windows

*Corresponding author: Radha Goyal, Scientist Fellow, National Environmental Engineering Research Institute (NEERI), Delhi Zonal Laboratory, CSIR R\&D centre, Naraina Industrial Area, Delhi, India, E-mail: Sunday.oyedepo@covenantuniversity.edu.ng

Received July 27, 2012; Accepted August 26, 2012; Published September 10, 2012

Citation: Goyal R, Khare M (2012) Simulation of Airflow and Wind Pressure Coefficient in a Naturally Ventilated Classroom Model Using Environmental Wind Tunnel and CFD Modelling. J Civil Environ Eng S1:001. doi:10.4172/2165-784X. S1-001

Copyright: (c) 2012 Goyal, et al. This is an open-access article distributed under the terms of the Creative Commons Attribution License, which permits unrestricted use, distribution, and reproduction in any medium, provided the original author and source are credited. 
with $1.65 \mathrm{~m} \times 0.60 \mathrm{~m}$ dimensions, opening towards main traffic road; two ventilators and one door with $1.29 \mathrm{~m} \times 0.63 \mathrm{~m}$ and $2.23 \mathrm{~m} \times 1.7 \mathrm{~m}$ dimensions respectively, opening in corridor of the school (Figure 1(a-c)). A miniature model of selected classrooms has been prepared using Perspex sheet at Environmental Engineering Laboratory of IIT Delhi (Figure 2). The model has been fabricated to a scale $(1.0 \mathrm{~cm}: 50.0$ $\mathrm{cm}$ ), which lied within the turbulent boundary layer in the wind tunnel resembling the real existing conditions with the observed wind velocity profile for the wind tunnel (Figure 3). The classrooms being studied and modeled are at the first floor of the school building. The ground floor has been considered as the dead space with no openings so that it will not interfere the interior airflow distribution at the selected floor. The model was placed in an open circuit, low speed, suction type EWT located at Applied Mechanics Department of IIT Delhi. The constructional features of the EWT are shown in figure 4.

For measurement of pressure, points were chosen in such a way that they represent the airflow pattern in the regions where the effects of pollutants entering the space can be critical. The average height of children in classrooms was considered to be $110.0 \mathrm{~cm}$ and the average sitting level is about $50.0 \mathrm{~cm}$. Thus, measurements have been done at scaled heights of $1.0 \mathrm{~cm}$ and $2.0 \mathrm{~cm}$ from the floor level to represent

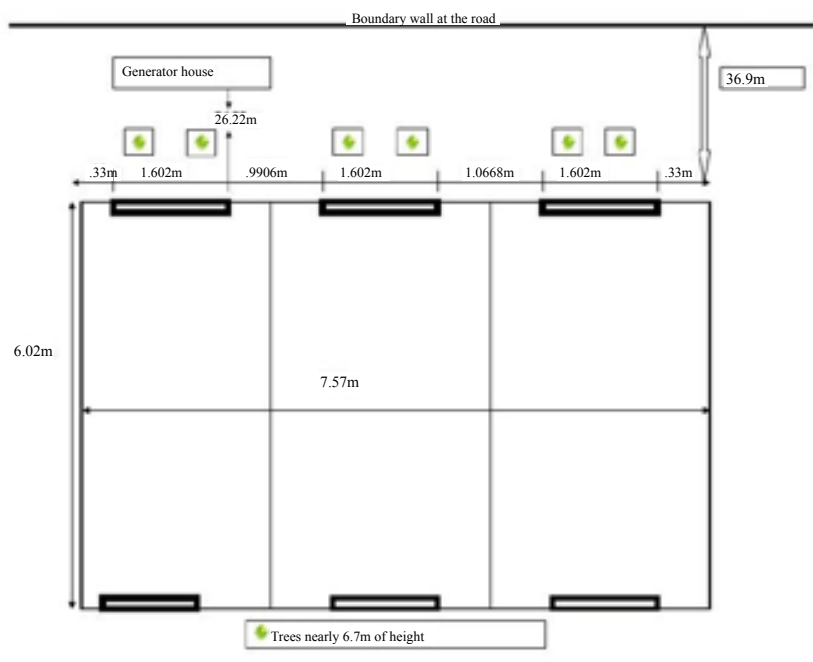

Figure 1a: The plan view of the classroom selected for study.

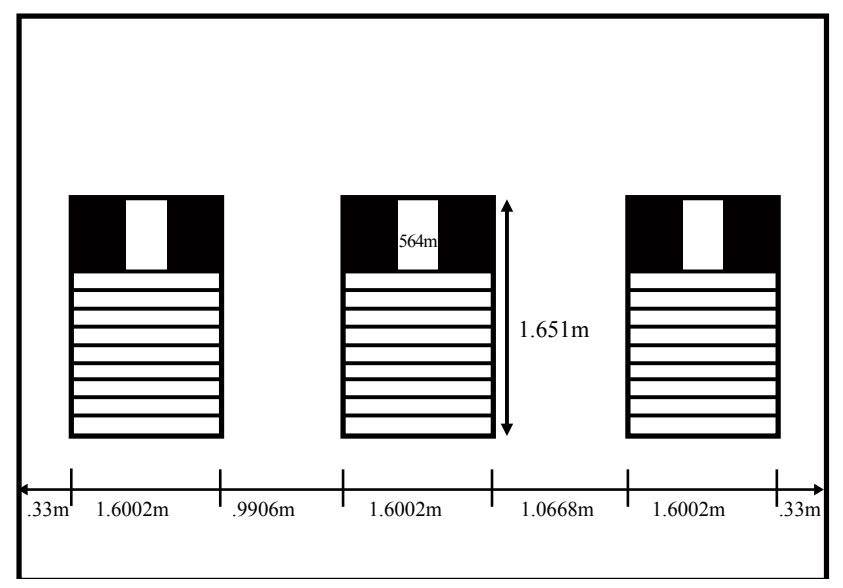

Figure 1b: The elevation view of the room facing the road.

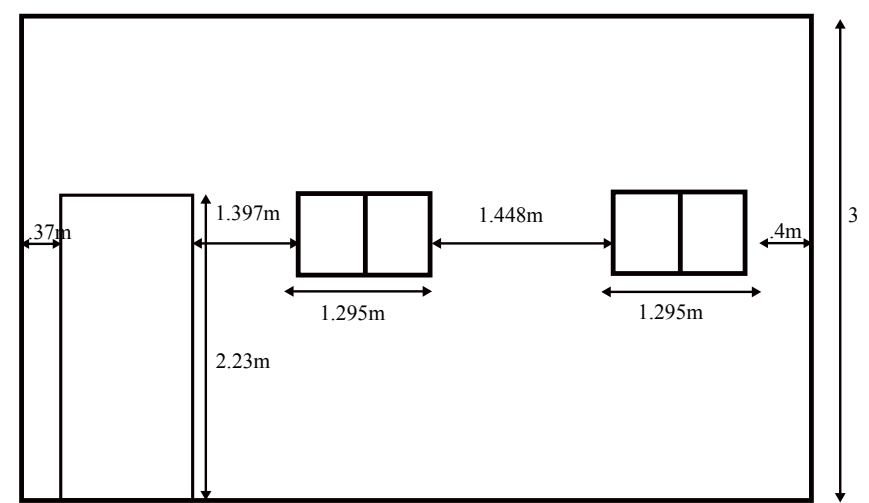

Figure 1c: The elevation view of the room facing the corridor.

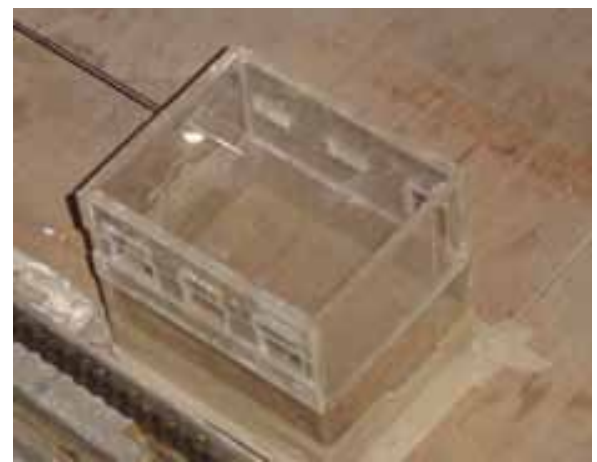

Figure 2: Classroom model made of Perspex for environmental Wind tunne study.

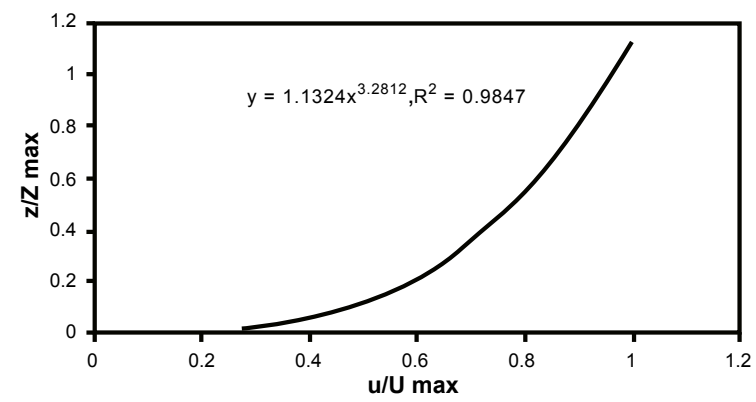

Figure 3: The wind velocity profile generated in the Environmental wind tunnel.

the average sitting and standing levels for children. The measurements have been carried out at each selected height on 4 sections across the width of the space representing the 4 rows of benches in the classroom and at 5 points along the length of the space (total 18 points) as shown in the figure 5 . The static pressure at these levels was measured using a Micromanometer BETZ 2000. Furness Control differential pressure transducer, coupled to Scanivalve port selectors were used for measuring the mean surface pressures along the center section of the building surface. The tunnel reference pressure head has also been measured using a pitot tube positioned away from flow disturbances. The measurements were carried out at different configurations of the building as well as changing wind direction to study the effect of these changes on the ventilation pattern of the building. 


\section{Methodology}

The aerodynamic simulation of wind tunnel to urban area, representing large city centre, has been done by making power law coefficient $(\mathrm{l} / \mathrm{n})$ to range 0.27 to 0.33 . The $(\mathrm{I} / \mathrm{n})$ obtained in wind tunnel after simulation is 0.304 . The experiments have been designed to determine the airflow distribution inside the classroom model placed in EWT at wind incidence angles of $0^{\circ}, 45^{\circ}, 90^{\circ}$ and $135^{\circ}$ with the wind direction. The classroom has been investigated at configurations of fully opened, partially opened as well as completely closed windows, door and ventilators, which represents the airflow distribution expected to happen in summer and winter months in India. The wind velocity and tunnel reference pressure head have been measured at inlet and outlet of different openings using an anemomaster at a distance of $50.0 \mathrm{~cm}$ upstream of the turntable. The point was considered to be away from flow disturbances. The $\mathrm{Cp}$ values have been calculated at all the critical points and at all the configurations of wind incidence angle using the following equation [6].

$$
C_{p}=\left(P-P_{\infty}\right) /\left(1 / 2 \rho v_{\infty}^{2}\right)
$$

Where, $\left(\mathrm{P}-\mathrm{P}_{\infty}\right)$ is the difference of differential pressure measured and the reference pressure, $\rho$ is mass density of air and $\mathrm{V}_{\infty}$ is mean wind velocity.

An alternative approach of computational fluid dynamics (CFD) has also been used to calculate the wind velocity and turbulent intensity and to observe the airflow distributions in and around the classroom

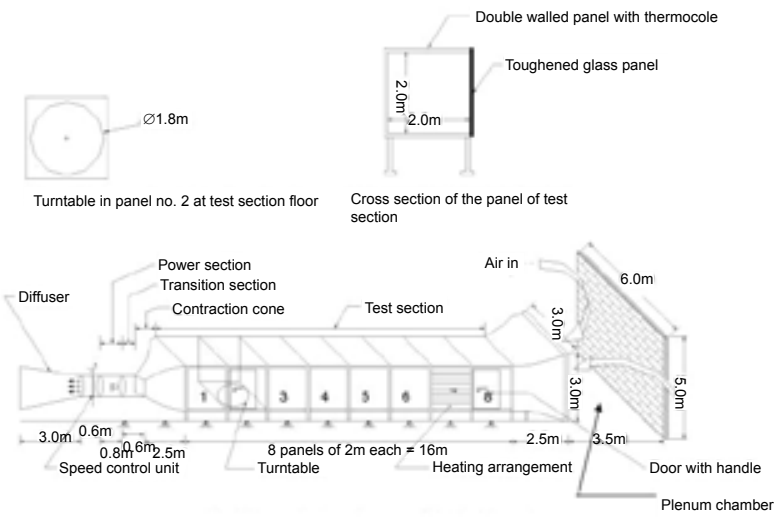

Figure 4: Layout and constructional features of the Environmental wind tunnel.

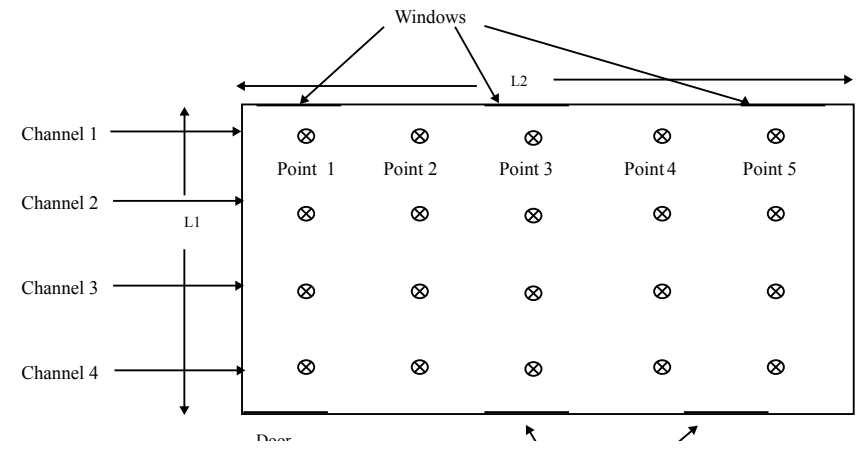

Figure 5: The selected measurement points on the plan view of the classroom model.

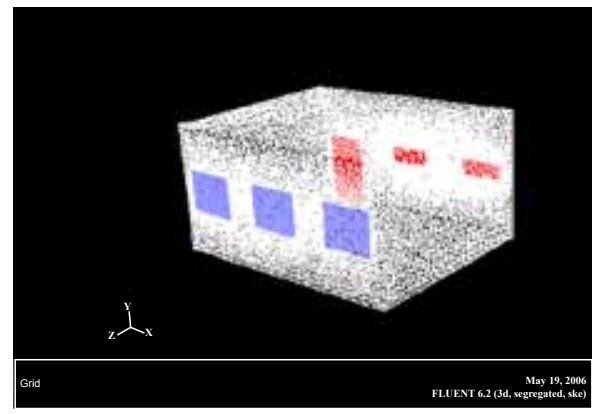

Figure 6: Classroom model made in GAMBIT, FLUENT, 6.2.
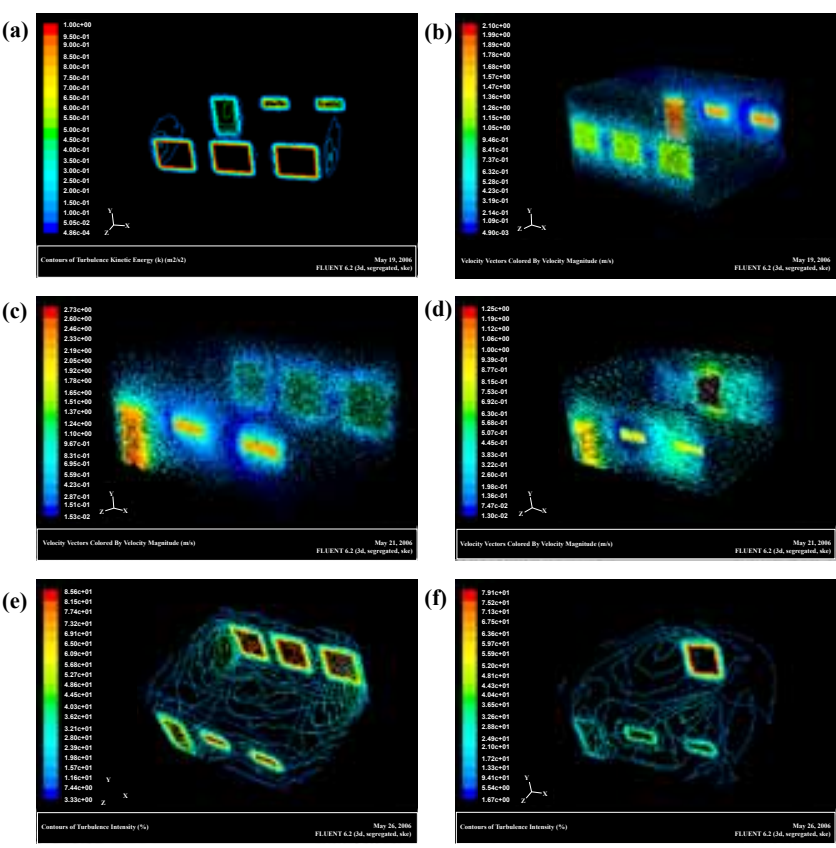

Figure 7: Results of wind velocity and turbulent intensity in classroom model generated in FLUENT. a: Turbulence contours. b: Wind velocity contours. c: Wind velocity distribution when all inlets and outlets are open. d: Turbulent intensity distribution when all inlets and outlets are open. e: Wind velocity distribution when inlets. f: Turbulent intensity distribution when inlets and outlets are partially open and outlets are partially open.

model. The modeled classroom grid has been developed and simulated in GAMBIT, a preprocessor of FLUENT software, version 6.2 (Figure 6).

\section{Results and Discussion}

The experimental results of $C_{p}$ values calculated under varying wind incidence angles and windows and door opening configurations are listed in Tables 1-4. A closer investigation of the listed values of $C_{p}$ indicates certain features. Those are:

- As we go up from the floor, the values of the $C_{p}$ show a decreasing trend. This indicates that the air near ground levels goes up due to stack effect produced as a result of pressure gradients created inside the naturally ventilated classroom. The significance of this feature in terms of IAQ inside the classroom indicate that if any pollutant enters the classroom from the windows, it can escape out of the ventilators located at upper levels of windows. 
Table 1: Values of $C_{p}$ calculated at ' 0 ' wind incidence angle.

\begin{tabular}{|c|c|c|c|c|c|c|c|c|c|c|c|c|c|c|c|}
\hline \multicolumn{16}{|c|}{ Fully open door and windows } \\
\hline \multicolumn{4}{|c|}{ Channel 1} & \multicolumn{4}{|c|}{ Channel 2} & \multicolumn{4}{|c|}{ Channel 3} & \multicolumn{4}{|c|}{ Channel 4} \\
\hline $\mathrm{H}=1 \mathrm{~cm}$ & $\mathrm{Cp}$ & $\mathrm{H}=2 \mathrm{~cm}$ & Cp & $\mathrm{H}=1 \mathrm{~cm}$ & Cp & $\mathrm{H}=2 \mathrm{~cm}$ & Cp & $\mathrm{H}=1 \mathrm{~cm}$ & Cp & $\mathrm{H}=2 \mathrm{~cm}$ & $\mathrm{Cp}$ & $\mathrm{H}=1 \mathrm{~cm}$ & $\mathrm{Cp}$ & $\mathrm{H}=2 \mathrm{~cm}$ & Cp \\
\hline-0.4 & 0 & -0.4 & 0 & -0.35 & 0.049475 & -0.5 & -0.09895 & -0.3 & 0.09895 & -0.4 & 0 & -0.6 & -0.1979 & -0.35 & 0.049475 \\
\hline-0.35 & 0.049475 & -0.4 & 0 & -0.4 & 0 & -0.45 & -0.049475 & -0.35 & 0.049475 & -0.35 & 0.049475 & -0.5 & -0.09895 & -0.45 & -0.04948 \\
\hline-0.4 & 0 & -0.4 & 0 & -0.5 & -0.09895 & -0.55 & -0.148425 & -0.4 & 0 & -0.5 & -0.09895 & -0.45 & -0.049475 & -0.4 & 0 \\
\hline-0.4 & 0 & -0.5 & -0.09895 & -0.45 & -0.049475 & -0.55 & -0.148425 & -0.35 & 0.049475 & -0.35 & 0.049475 & -0.5 & -0.09895 & -0.35 & 0.049475 \\
\hline-0.3 & 0.09895 & -0.4 & 0 & -0.4 & 0 & -0.45 & -0.049475 & -0.4 & 0 & -0.45 & -0.049475 & -0.5 & -0.09895 & -0.4 & 0 \\
\hline \multicolumn{16}{|c|}{ Partially open door and windows } \\
\hline \multicolumn{4}{|c|}{ Channel 1} & \multicolumn{4}{|c|}{ Channel 2} & \multicolumn{4}{|c|}{ Channel 3} & \multicolumn{4}{|c|}{ Channel 4} \\
\hline $\mathrm{H}=1 \mathrm{~cm}$ & Cp & $\mathrm{H}=2 \mathrm{~cm}$ & Cp & $\mathrm{H}=1 \mathrm{~cm}$ & Cp & $\mathrm{H}=2 \mathrm{~cm}$ & Cp & $\mathrm{H}=1 \mathrm{~cm}$ & Cp & $\mathrm{H}=2 \mathrm{~cm}$ & Cp & $\mathrm{H}=1 \mathrm{~cm}$ & Cp & $\mathrm{H}=2 \mathrm{~cm}$ & Cp \\
\hline-0.35 & 0.049475 & -0.5 & -0.09895 & -0.4 & 0 & -0.5 & -0.09895 & -0.3 & 0.09895 & -0.35 & 0.049475 & -0.4 & 0 & -0.45 & -0.04948 \\
\hline-0.4 & 0 & -0.5 & -0.09895 & -0.35 & 0.049475 & -0.4 & 0 & -0.4 & 0 & -0.45 & -0.049475 & -0.4 & 0 & -0.45 & -0.04948 \\
\hline-0.3 & 0.09895 & -0.45 & -0.049475 & -0.4 & 0 & -0.45 & -0.049475 & -0.4 & 0 & -0.4 & 0 & -0.5 & -0.09895 & -0.4 & 0 \\
\hline-0.35 & 0.049475 & -0.6 & -0.1979 & -0.4 & 0 & -0.45 & -0.049475 & -0.4 & 0 & -0.4 & 0 & -0.4 & 0 & -0.5 & -0.09895 \\
\hline-0.4 & 0 & -0.4 & 0 & -0.4 & 0 & -0.5 & -0.09895 & -0.35 & 0.049475 & -0.4 & 0 & -0.4 & 0 & -0.4 & 0 \\
\hline
\end{tabular}

Table 2: Values of $C_{p}$ calculated at ' $45^{\circ}$ ' wind incidence angle.

Fully open door and windows

\begin{tabular}{|c|c|c|c|c|c|c|c|c|c|c|c|c|c|c|c|}
\hline \multicolumn{4}{|c|}{ Channel 1} & \multicolumn{4}{|c|}{ Channel 2} & \multicolumn{4}{|c|}{ Channel 3} & \multicolumn{4}{|c|}{ Channel 4} \\
\hline $\mathrm{H}=1 \mathrm{~cm}$ & $\mathrm{Cp}$ & $\mathrm{H}=2 \mathrm{~cm}$ & $\mathrm{Cp}$ & $\mathrm{H}=1 \mathrm{~cm}$ & $\mathrm{Cp}$ & $\mathrm{H}=2 \mathrm{~cm}$ & $\mathrm{Cp}$ & $\mathrm{H}=1 \mathrm{~cm}$ & $\mathrm{Cp}$ & $\mathrm{H}=2 \mathrm{~cm}$ & $\mathrm{Cp}$ & $\mathrm{H}=1 \mathrm{~cm}$ & $\mathrm{Cp}$ & $\mathrm{H}=2 \mathrm{~cm}$ & $\mathrm{Cp}$ \\
\hline-0.3 & 0.09895 & -0.4 & 0 & -0.4 & 0 & -0.45 & -0.049475 & -0.45 & -0.049475 & -0.4 & 0 & -0.5 & -0.09895 & -0.35 & 0.049475 \\
\hline-0.4 & 0 & -0.5 & -0.09895 & -0.5 & -0.09895 & -0.5 & -0.09895 & -0.4 & 0 & -0.4 & 0 & -0.45 & -0.049475 & -0.3 & 0.09895 \\
\hline-0.35 & 0.049475 & -0.45 & -0.049475 & -0.35 & 0.049475 & -0.4 & 0 & -0.4 & 0 & -0.5 & -0.09895 & -0.4 & 0 & -0.3 & 0.09895 \\
\hline-0.35 & 0.049475 & -0.45 & -0.049475 & -0.35 & 0.049475 & -0.4 & 0 & -0.5 & -0.09895 & -0.35 & 0.049475 & -0.45 & -0.049475 & -0.25 & 0.148425 \\
\hline-0.4 & 0 & -0.6 & -0.1979 & -0.5 & -0.09895 & -0.5 & -0.09895 & -0.5 & -0.09895 & -0.4 & 0 & -0.4 & 0 & -0.25 & 0.148425 \\
\hline \multicolumn{16}{|c|}{ Partially open door and windows } \\
\hline \multicolumn{4}{|c|}{ Channel 1} & \multicolumn{4}{|c|}{ Channel 2} & \multicolumn{4}{|c|}{ Channel 3} & \multicolumn{4}{|c|}{ Channel 4} \\
\hline $\mathrm{H}=1 \mathrm{~cm}$ & $\mathrm{Cp}$ & $\mathrm{H}=2 \mathrm{~cm}$ & Cp & $\mathrm{H}=1 \mathrm{~cm}$ & $\mathrm{Cp}$ & $\mathrm{H}=2 \mathrm{~cm}$ & $\mathrm{Cp}$ & $\mathrm{H}=1 \mathrm{~cm}$ & Cp & $\mathrm{H}=2 \mathrm{~cm}$ & Cp & $\mathrm{H}=1 \mathrm{~cm}$ & $\mathrm{Cp}$ & $\mathrm{H}=2 \mathrm{~cm}$ & $\mathrm{Cp}$ \\
\hline-0.5 & -0.09895 & -0.4 & 0 & -0.4 & 0 & -0.45 & -0.049475 & -0.4 & 0 & -0.45 & -0.049475 & -0.5 & -0.09895 & -0.4 & 0 \\
\hline-0.4 & 0 & -0.45 & -0.049475 & -0.4 & 0 & -0.45 & -0.049475 & -0.45 & -0.049475 & -0.45 & -0.049475 & -0.45 & -0.049475 & -0.3 & 0.09895 \\
\hline-0.4 & 0 & -0.5 & -0.09895 & -0.3 & 0.09895 & -0.5 & -0.09895 & -0.45 & -0.049475 & -0.5 & -0.09895 & -0.4 & 0 & -0.4 & 0 \\
\hline-0.45 & -0.04948 & -0.4 & 0 & -0.4 & 0 & -0.4 & 0 & -0.4 & 0 & -0.5 & -0.09895 & -0.4 & 0 & -0.45 & -0.04948 \\
\hline-0.45 & -0.04948 & -0.55 & -0.148425 & -0.4 & 0 & -0.45 & -0.049475 & -0.45 & -0.049475 & -0.45 & -0.049475 & -0.45 & -0.049475 & -0.45 & -0.04948 \\
\hline
\end{tabular}

Table 3: Values of $C_{p}$ calculated at ' $90^{\circ}$ ' wind incidence angle.

\section{Fully open door and windows}

\begin{tabular}{|c|c|c|c|c|c|c|c|c|c|c|c|c|c|c|c|}
\hline \multicolumn{4}{|c|}{ Channel 1} & \multicolumn{4}{|c|}{ Channel 2} & \multicolumn{4}{|c|}{ Channel 3} & \multicolumn{4}{|c|}{ Channel 4} \\
\hline $\mathrm{H}=1 \mathrm{~cm}$ & Cp & $\mathrm{H}=2 \mathrm{~cm}$ & Cp & $\mathrm{H}=1 \mathrm{~cm}$ & $\mathrm{Cp}$ & $\mathrm{H}=2 \mathrm{~cm}$ & Cp & $\mathrm{H}=1 \mathrm{~cm}$ & $\mathrm{Cp}$ & $\mathrm{H}=2 \mathrm{~cm}$ & Cp & $\mathrm{H}=1 \mathrm{~cm}$ & Cp & $\mathrm{H}=2 \mathrm{~cm}$ & Cp \\
\hline-0.4 & 0 & -0.55 & -0.148425 & -0.5 & -0.09895 & -0.55 & -0.148425 & -0.4 & 0 & -0.5 & -0.09895 & -0.5 & -0.09895 & -0.4 & 0 \\
\hline-0.5 & -0.09895 & -0.55 & -0.148425 & -0.5 & -0.09895 & -0.4 & 0 & -0.5 & -0.09895 & -0.45 & -0.049475 & -0.5 & -0.09895 & -0.45 & -0.04948 \\
\hline-0.4 & 0 & -0.45 & -0.049475 & -0.5 & -0.09895 & -0.4 & 0 & -0.5 & -0.09895 & -0.5 & -0.09895 & -0.5 & -0.09895 & -0.5 & -0.09895 \\
\hline-0.45 & -0.04948 & -0.45 & -0.049475 & -0.4 & 0 & -0.5 & -0.09895 & -0.4 & 0 & -0.4 & 0 & -0.45 & -0.049475 & -0.55 & -0.14843 \\
\hline-0.45 & -0.04948 & -0.45 & -0.049475 & -0.5 & -0.09895 & -0.55 & -0.148425 & -0.45 & -0.049475 & -0.45 & -0.049475 & -0.5 & -0.09895 & -0.5 & -0.09895 \\
\hline \multicolumn{16}{|c|}{ Partially open door and windows } \\
\hline \multicolumn{4}{|c|}{ Channel 1} & \multicolumn{4}{|c|}{ Channel 2} & \multicolumn{4}{|c|}{ Channel 3} & \multicolumn{4}{|c|}{ Channel 4} \\
\hline $\mathrm{H}=1 \mathrm{~cm}$ & $\mathrm{Cp}$ & $\mathrm{H}=2 \mathrm{~cm}$ & Cp & $\mathrm{H}=1 \mathrm{~cm}$ & Cp & $\mathrm{H}=2 \mathrm{~cm}$ & Cp & $\mathrm{H}=1 \mathrm{~cm}$ & Cp & $\mathrm{H}=2 \mathrm{~cm}$ & Cp & $\mathrm{H}=1 \mathrm{~cm}$ & Cp & $\mathrm{H}=2 \mathrm{~cm}$ & Cp \\
\hline-0.45 & -0.04948 & -0.45 & -0.049475 & -0.4 & 0 & -0.45 & -0.049475 & -0.5 & -0.09895 & -0.5 & -0.09895 & -0.55 & -0.148425 & -0.55 & -0.14843 \\
\hline-0.5 & -0.09895 & -0.55 & -0.148425 & -0.5 & -0.09895 & -0.5 & -0.09895 & -0.45 & -0.049475 & -0.5 & -0.09895 & -0.4 & 0 & -0.45 & -0.04948 \\
\hline-0.45 & -0.04948 & -0.55 & -0.148425 & -0.4 & 0 & -0.55 & -0.148425 & -0.4 & 0 & -0.45 & -0.049475 & -0.45 & -0.049475 & -0.45 & -0.04948 \\
\hline-0.4 & 0 & -0.6 & -0.1979 & -0.5 & -0.09895 & -0.5 & -0.09895 & -0.5 & -0.09895 & -0.55 & -0.148425 & -0.5 & -0.09895 & -0.5 & -0.09895 \\
\hline-0.5 & -0.09895 & -0.65 & -0.247375 & -0.4 & 0 & -0.55 & -0.148425 & -0.4 & 0 & -0.55 & -0.148425 & -0.5 & -0.09895 & -0.5 & -0.09895 \\
\hline
\end{tabular}

- The values of $C_{p}$ at a wind incidence angle of $90^{\circ}$ show a trend of being essentially negative. This indicates that at this configuration, there is a large amount of inflow of air into the interior of the classroom, which also increases the probability of pollutants to enter inside the room from outside and can have an adverse effect on the IAQ of classroom and further on its occupants.
- The values of $C_{p}$ at wind incidence angle of $135^{\circ}$ are essentially zero. This indicates that at this angle the air inside the room will not have much interaction with the outside air. This configuration can either becomes dangerous for the occupants because the pollutants inside the room will not be able to escape out and may create health hazards for the occupants. Thus, the $C_{p}$ values can serve as an important input parameter for 
Citation: Goyal R, Khare M (2012) Simulation of Airflow and Wind Pressure Coefficient in a Naturally Ventilated Classroom Model Using Environmental Wind Tunnel and CFD Modelling. J Civil Environ Eng S1:001. doi:10.4172/2165-784X.S1-001

Table 4: Values of $C_{p}$ calculated at ' $135^{\circ}$ ' wind incidence angle.

Fully open door and windows

\begin{tabular}{|c|c|c|c|c|c|c|c|c|c|c|c|c|c|c|c|}
\hline \multicolumn{4}{|c|}{ Channel 1} & \multicolumn{4}{|c|}{ Channel 2} & \multicolumn{4}{|c|}{ Channel 3} & \multicolumn{4}{|c|}{ Channel 4} \\
\hline $\mathrm{H}=1 \mathrm{~cm}$ & $\mathrm{Cp}$ & $\mathrm{H}=2 \mathrm{~cm}$ & $\mathrm{Cp}$ & $\mathrm{H}=1 \mathrm{~cm}$ & $\mathrm{Cp}$ & $\mathrm{H}=2 \mathrm{~cm}$ & $\mathrm{Cp}$ & $\mathrm{H}=1 \mathrm{~cm}$ & $\mathrm{Cp}$ & $\mathrm{H}=2 \mathrm{~cm}$ & Cp & $\mathrm{H}=1 \mathrm{~cm}$ & $\mathrm{Cp}$ & $\mathrm{H}=2 \mathrm{~cm}$ & $\mathrm{Cp}$ \\
\hline-0.45 & -0.04948 & -0.55 & -0.148425 & -0.4 & 0 & -0.45 & -0.049475 & -0.35 & 0.049475 & -0.3 & 0.09895 & -0.4 & 0 & -0.35 & 0.049475 \\
\hline-0.4 & 0 & -0.4 & 0 & -0.45 & -0.049475 & -0.35 & 0.049475 & -0.4 & 0 & -0.35 & 0.049475 & -0.5 & -0.09895 & -0.4 & 0 \\
\hline-0.4 & 0 & -0.4 & 0 & -0.4 & 0 & -0.4 & 0 & -0.45 & -0.049475 & -0.4 & 0 & -0.35 & 0.049475 & -0.4 & 0 \\
\hline-0.35 & 0.049475 & -0.4 & 0 & -0.35 & 0.049475 & -0.45 & -0.049475 & -0.4 & 0 & -0.35 & 0.049475 & -0.4 & 0 & -0.45 & -0.04948 \\
\hline-0.35 & 0.049475 & -0.35 & 0.049475 & -0.45 & -0.049475 & -0.4 & 0 & -0.35 & 0.049475 & -0.35 & 0.049475 & -0.4 & 0 & -0.4 & 0 \\
\hline
\end{tabular}

\section{Partially open door and windows}

\begin{tabular}{|c|c|c|c|c|c|c|c|c|c|c|c|c|c|c|c|}
\hline \multicolumn{4}{|c|}{ Channel 1} & \multicolumn{4}{|c|}{ Channel 2} & \multicolumn{4}{|c|}{ Channel 3} & \multicolumn{4}{|c|}{ Channel 4} \\
\hline $\mathrm{H}=1 \mathrm{~cm}$ & $\mathrm{Cp}$ & $\mathrm{H}=2 \mathrm{~cm}$ & $\mathrm{Cp}$ & $\mathrm{H}=1 \mathrm{~cm}$ & $\mathrm{Cp}$ & $\mathrm{H}=2 \mathrm{~cm}$ & $\mathrm{Cp}$ & $\mathrm{H}=1 \mathrm{~cm}$ & $\mathrm{Cp}$ & $\mathrm{H}=2 \mathrm{~cm}$ & $\mathrm{Cp}$ & $\mathrm{H}=1 \mathrm{~cm}$ & $\mathrm{Cp}$ & $\mathrm{H}=2 \mathrm{~cm}$ & $\mathrm{Cp}$ \\
\hline-0.35 & 0.049475 & -0.4 & 0 & -0.4 & 0 & -0.45 & -0.049475 & -0.4 & 0 & -0.5 & -0.09895 & -0.35 & 0.049475 & -0.4 & 0 \\
\hline-0.4 & 0 & -0.35 & 0.049475 & -0.4 & 0 & -0.4 & 0 & -0.35 & 0.049475 & -0.35 & 0.049475 & -0.35 & 0.049475 & -0.4 & 0 \\
\hline-0.4 & 0 & -0.4 & 0 & -0.4 & 0 & -0.35 & 0.049475 & -0.45 & -0.049475 & -0.4 & 0 & -0.45 & -0.049475 & -0.4 & 0 \\
\hline-0.4 & 0 & -0.45 & -0.049475 & -0.5 & -0.09895 & -0.4 & 0 & -0.35 & 0.049475 & -0.4 & 0 & -0.4 & 0 & -0.3 & 0.09895 \\
\hline-0.35 & 0.049475 & -0.4 & 0 & -0.4 & 0 & -0.45 & -0.049475 & -0.4 & 0 & -0.35 & 0.049475 & -0.35 & 0.049475 & -0.35 & 0.049475 \\
\hline
\end{tabular}

Table 5: Variations estimated in wind velocity and turbulent intensity using CFD modeling.

\begin{tabular}{|c|c|c|}
\hline Opening conditions & Variation in turbulence intensity (\%) & Variation in wind velocity $(\mathrm{m} / \mathrm{s})$ \\
\hline When all inlets and outlets open & $3.30-85.6$ & $1.53 E-3-2.73$ \\
\hline When one extreme window closed & $2.76-79.2$ & $1.92 \mathrm{E}-2-1.91$ \\
\hline When two extreme windows closed & $1.67-79.1$ & 1.30E-2 - 1.25 \\
\hline When door closed, and all windows open & $37.3-227$ & $2.10 \mathrm{E}-2-8.90$ \\
\hline
\end{tabular}

understanding the natural ventilation in buildings and further its influence on IAQ.

Further, the velocity distribution and turbulence intensity inside the modeled classroom has been measured using $\mathrm{k}-\varepsilon$ model at different opening configurations. Table 5 shows the values of variations in velocity and turbulence intensity under varying opening and closing configurations. The results of FLUENT study shown in figure 7 (a-f) that the maximum turbulence intensity and velocity observes under partially closed conditions, i.e. when door is closed and all the windows and ventilators are opened. Whereas the minimum values are observed when two extreme windows are closed and door is open.

\section{Conclusions}

The interpretation of observed results of the study shows that the values of $C_{p}$ for naturally ventilated classroom model can serve as an important input for further ventilation studies on such indoor spaces. The present study has certain limitations as the measurement of concentrations of tracer gas at the selected points could not be carried out due to non-availability of equipments in the laboratory. Once the tracer gas study will also be carried out at selected points, it will be easier to understand the relationship and inter-dependence of pressure distribution and airflow distribution inside the simulated indoor space and further will help to investigate the IAQ in such naturally ventilated spaces with varying environmental conditions and building configurations.

\section{Acknowledgement}

The authors thank Professor K.K. Choudhary, Applied Mechanics Department of IIT Delhi to provide wind tunnel facility to carry out the present study. They also thank Raghvendra Reddy, Abinav Aggarwal and Saurabh Taneja for their immense help in conducting the experiments.

\section{References}

1. Liddament M (1996) A guide to energy efficient ventilation, Air infiltration and Ventilation Center, Coventry, UK.

2. Alexander D, Jenkins $H$, Jones $P$ (1997) Investigating the effects of wind on natural ventilation design of commercial buildings, Proceedings, Sustainable Building, Abingdon, Oxfordshire, UK, 141-148.

3. Kabrhel M, Jirsák M, Bittner M, Kabele K, Zachoval D (2007) Exterior Climate and Building Ventilation. In Proceedings of Clima 2007 WellBeing Indoor.

4. ASHRAE (2001) "ASHRAE Handbook of Fundamentals". Published by the American Society of Heating, Refrigeration and Air-Conditioning Engineers, Inc., 345 East $47^{\text {th }}$ St. New York, N.Y., 10017.

5. Richards PJ, Hoxey RP, Short LJ (2001) Wind pressures on a $6 \mathrm{~m}$ cube. Wind Eng Ind Aerod 89: 1553-1564.

6. Eftekhari MM, Holmes M, Marjanovic LD, Hanby V (2002) Air flow distribution for different distribution wind pressure coefficient values in naturally ventilated room. ASHRAE Transactions 2: 1233-1240.

7. Wiren BG (1983) Effects of surrounding buildings on wind pressure distributions and ventilative heat losses for a single family house. J Wind Eng Ind Aerod 15: 15-26.

8. JiaY, Sill BL (1998) Pressures on a cube embedded in a uniform roughness field of variable spacing density. J Wind Eng Ind Aerod 77: 491-501.

9. Hussain M, Lee BE (1988) A wind tunnel study of mean pressure forces acting on large group of low-rise buildings. J Wind Eng Ind Aerodyn 31: 41-66.

10. Kim JJ, Baik JJ, Chun HY (2001) Two-dimensional numerical modelling of flow and dispersion in the presence of hill and buildings. J Wind Eng Ind Aerod 89 947-966.

11. Chang $\mathrm{CH}$, Meroney $\mathrm{RN}$ (2003) Concentration and flow distribution in urban street canyons: wind-tunnel and computational data. J Wind Eng Ind Aerod 91 1141-1154. 
Citation: Goyal R, Khare M (2012) Simulation of Airflow and Wind Pressure Coefficient in a Naturally Ventilated Classroom Model Using Environmental Wind Tunnel and CFD Modelling. J Civil Environ Eng S1:001. doi:10.4172/2165-784X.S1-001

Page 6 of 6

12. Grosso M (1992) Wind pressure distribution around buildings: a parametric model. Energy and Buildings 18: 101-131.

13. Jiang $Y$, Alexander D, Jenkins $H$, Arthur $R$, Chen $Q$ (2003) Natural ventilation in buildings: Measurements in a wind tunnel and numerical simulation with largeeddy simulation. J Wind Eng Ind Aerod 91: 331-353.
14. Kato S, Murakami S, Mochoda A, Akabayashi S, Tominaga Y, (1992) Velocity pressure field of cross ventilation with open windows analyzed by wind tunne and numerical simulation. J Wind Eng Ind Aerod 44: 2575-2586. 